\title{
АНАЛИЗ ПРИРОДНЫХ ФАКТОРОВ ЗАЩИЩЕННОСТИ ОТ ЗАГРЯЗНЕНИЯ ОСНОВНЫХ ВОДОНОСНЫХ КОМПЛЕКСОВ ЮГО-ЗАПАДНОЙ ЧАСТИ ВОРОНЕЖСКОЙ ОБЛАСТИ
}

\author{
С. П. Пасмарнова \\ Воронежский государственный университет \\ Поступила в редакцию 13 февраля 2019 г.
}

\begin{abstract}
Аннотация: рассматриваются природные условия защищенности от загрязнения кантемировско-берекского терригенного и верхнемелового карбонатно-терригенного водоносных комплексов, как основных, используемых для питьевого водоснабжения населения на территории югозападной части Воронежской области. Анализируются факторы (глубина залегания подземных вод, литологический состав и мощность слабопроницаемых отложений зоны аэрации), определяющие условия защищценности от загрязнения безнапорных водоносных подразделений. По совокупности факторов установлено, что на большей части территории исследований подземнье воды кантемировско-берекского терригенного комплекса являются весьма слабо защищенными от поверхностного загрязнения. Относительно высокая степень защищенности указанного горизонта отмечена на отдельных участках куполов водоразделов левобережья реки Богучарка. Подземные воды верхнемелового водоносного комплекса характеризуются широким диапазоном изменения условий защчищенности от загрязнения. В речных долинах, где зона аэрации сложена трещиноватыми мелами и песчаными породами, подземные воды являются весьма слабо защищеенныли. Надежно защищен от поступления загрязнения верхнемеловой водоносный комплекс на площади его перекрытия киевско-обуховским горизонтом, представленным глинами и глинистьми мергелями.
\end{abstract}

Ключевые слова: подземные воды, зона аэрации, слабопроницаемые отложения, литологический состав, защишщенность подземных вод.

\section{ANALYSIS OF NATURAL FACTORS OF SECURITY FROM POLUTION BASIC AQUIFERS SOUTH-WESTERN PART OF VORONEZH REGION}

\begin{abstract}
Kantemirov-Berek terrigenous and Upper Cretaceous carbonate-terrigenous aquifer complexes, as the main ones used for drinking water supply of the population in the south-western part of the Voronezh region. Factors are analyzed (depth of groundwater, lithological composition and thickness of low-permeable sediments of the aeration zone), determining the conditions for protection of free-flow aquifers from pollution. By a combination of factors, it has been established that in most of the research area the groundwater of the Kantemirov-Berek terrigenous complex is very poorly protected from surface contamination. A relatively high degree of protection of this horizon was noted in certain sections of the domes of the watersheds on the left bank of the Bogucharka River. Groundwaters of the Upper Cretaceous aquifer complex are characterized by a wide range of changes in conditions of protection from pollution. In river valleys, where the aeration zone is composed of fissured chalk and sandy rocks, groundwater is very poorly protected. It is reliably protected from contamination by the Upper Cretaceous aquiferous complex on the area of marls its overlap by the Kiev-Obukhov horizon, represented by clays and clay.

Key words: ground waters, an aeration zone, poorly nontight sedimentation, lithological structure, security of underground water.
\end{abstract}

Изучению условий защищенности подземных вод от поверхностного загрязнения в нашей стране уделяется особое внимание, начиная с середины прошлого века. В опубликованных ранее работах [1-3] автор проводил обзор существующих методов исследований. Также было отмечено, что при региональных 
исследованиях, когда неизвестно конкретное загрязняющее вещество, наиболее приемлемой для оценки условий защищенности подземных вод является методика, предложенная В. М. Гольдбергом [4]. В соответствии с ней условия защищенности от загрязнения безнапорных подземных вод характеризуются на основе сопоставления категорий защищенности, зависящих от глубины залегания уровня грунтовых вод, мощности и литологии слабопроницаемых отложений зоны аэрации. Чем выше категория, тем надежнее защищены подземные воды. При этом благоприятными условия защищенности можно назвать в том случае, когда защитные свойства зоны аэрации характеризуются $\mathrm{V}$ и более категориями.

На территории Воронежской области работы по изучению естественной защищенности подземных вод от загрязнения впервые были проведены в мелком масштабе (1:500 000) сотрудниками Воронежского госуниверситета под руководством А. Я. Смирновой в восьмидесятых годах прошлого столетия [5]. В 1998 2004 гг. в процессе проведения среднемасштабной гидрогеологической съемки на площади листов М-37XVI и M-37-XXII автором были построены карты защищенности от загрязнения первых от поверхности водоносных горизонтов. В последующие годы по результатам бурения разведочных скважин границы участков различной степени защищенности были уточнены.

В настоящей работе рассматриваются природные условия защищенности от загрязнения основных водоносных комплексов (кантемировско-берекского терригенного и верхнемелового карбонатно-терригенного), используемых для питьевого водоснабжения населения на территории юго-западной части Воронежской области. Следует отметить, что кантемировско-берекский водоносный комплекс повсеместно используются для частного водоснабжения с помощью каптированных родников, колодцев и неглубоких (до 20 м) буровых скважин, для централизованного водоснабжения на исследованной территории используются подземные воды верхнемеловых отложений. Указанные водоносные комплексы безнапорные.

Автор обращает внимание на то, что для верхнемелового водоносного комплекса на участках его перекрытия обводненными отложениями палеогенового возраста, дается оценка защищенности от поступления загрязняющих веществ из вышезалегающего кантемировско-берекского водоносного комплекса; на остальной территории - с поверхности земли.

Подземные воды кантемировско-берекского терригенного комплекса на большей части территории исследований являются весьма слабо защищенными от поверхностного загрязнения (рис. 1). Глубина их залегания повсеместно не превышает 30 м, а слабопроницаемые отложения зоны аэрации здесь представлены субаэральными суглинками мощностью 3 10 м [6]. На севере рассматриваемой территории условия защищенности подземных вод данного комплекса несколько выше (III-IV категории), что связа- но с появлением в разрезе зоны аэрации морены донского горизонта, представленной преимущественно тяжелыми суглинками [6]. Общая мощность слабопроницаемой толщи субаэральных и моренных суглинков составляет 5-15 метров. В юго-восточной части исследованной территории подземные воды названного выше комплекса также характеризуются нами как слабо защищенные (III-IV категории). Это обусловлено значительной мощностью субаэральных суглинков (10-20 м) и присутствием в разрезе берекских отложений глинистых прослоев суммарной мощностью до 4 м [7, 8]. На отдельных участках куполов водоразделов левобережья реки Богучарка, где водоносный комплекс перекрыт толщей субаэральных суглинков мощностью более 20 м, подземные воды можно считать защищенными (V-VI категории) от поверхностного загрязнения. Такая же степень защищенности кантемировско-берекского водоносного комплекса от поступления загрязнения с поверхности земли отмечена на небольшом по площади участке в северо-западной части рассматриваемой территории (южнее с. Надеждовка), где мощность ледниковых отложений достигает 25 м.

Подземные воды верхнемелового водоносного комплекса характеризуются широким диапазоном изменения условий защищенности от загрязнения (от весьма слабо защищенных до хорошо защищенных).

В речных долинах, где зона аэрации сложена трещиноватыми мелами и песчаными породами с маломощными прослоями глин, подземные воды являются весьма слабо защищенными (рис. 2). На водоразделах условия защищенности более благоприятные, при этом наблюдается закономерность возрастания степени защищенности грунтовых вод от подножия склонов к высоким отметкам водоразделов. Это обусловлено, с одной стороны - увеличением глубины залегания уровня подземных вод верхнемеловых отложений до 70-80 и более метров, с другой стороны - присутствием в разрезе зоны аэрации помимо субаэральных и ледниковых отложений глин и глинистых мергелей палеогенового возраста [7-9].

На склонах водоразделов защитные свойства зоны аэрации преимущественно характеризуются III и IV категориями за счет наличия слабопроницаемой толщи субаэральных и ледниковых отложений мощностью до 10 м. Хорошо защищенным от поступления загрязнения верхнемеловой водоносный комплекс является на площади его перекрытия водоупорным киевско-обуховским горизонтом, представленным глинами и глинистыми мергелями. Глубина залегания подземных вод здесь достигает $90 \mathrm{M}$, а суммарная мощность слабопроницаемых отложений составляет 20-25 м. На междуречье Малая Меженка - Дон, а также на отдельных участках в южной части рассматриваемой территории, где отмечена максимальная мощность (30 м) водоупорного киевско-обуховского горизонта, подземные воды верхнемеловых отложений можно считать надежно защищенными от поступления загрязнения. 


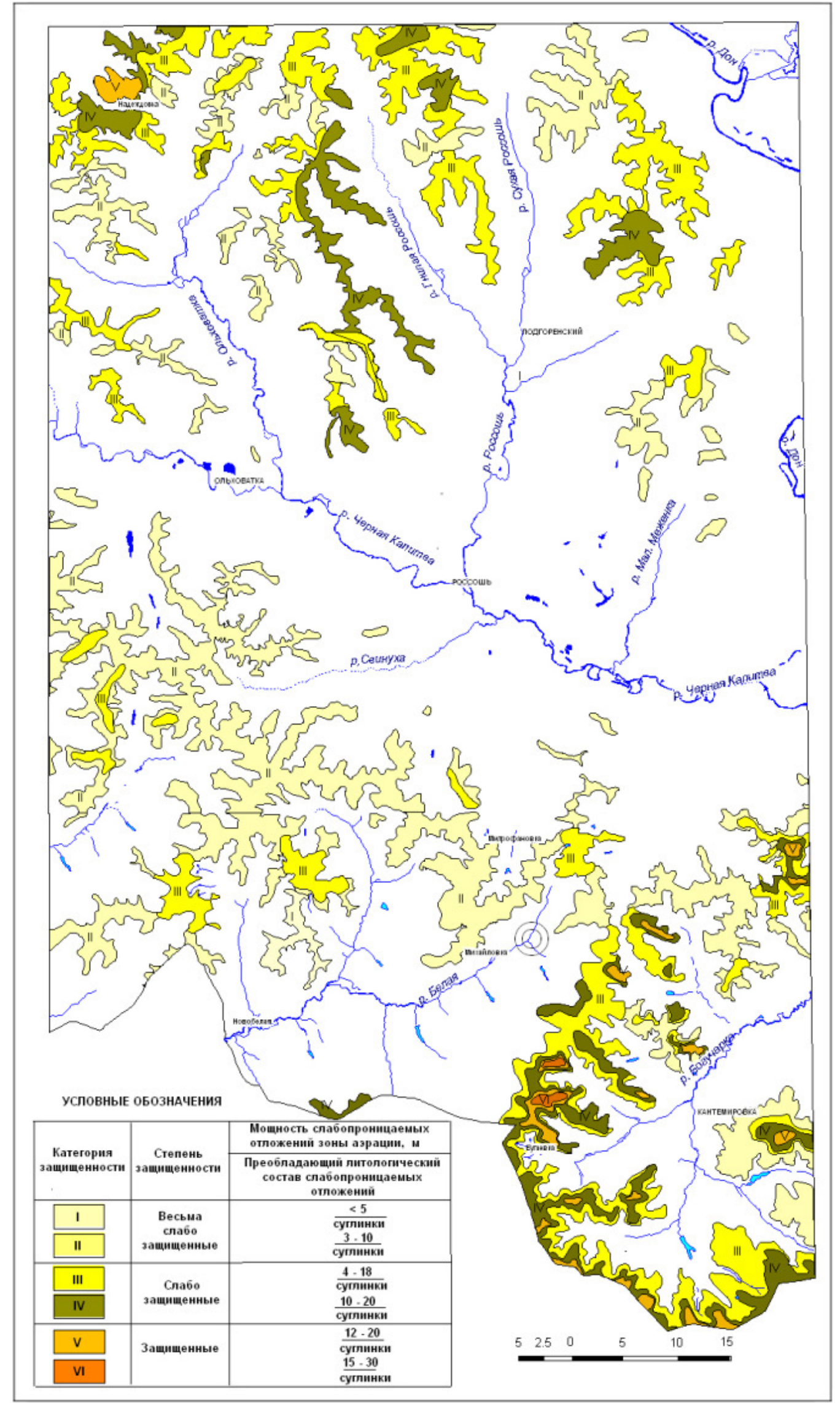

Puc.1. Схематическая карта защищенности от загрязнения кантемировско-берекского водоносного комплекса (С. П. Пасмарнова, 2017 г.). 


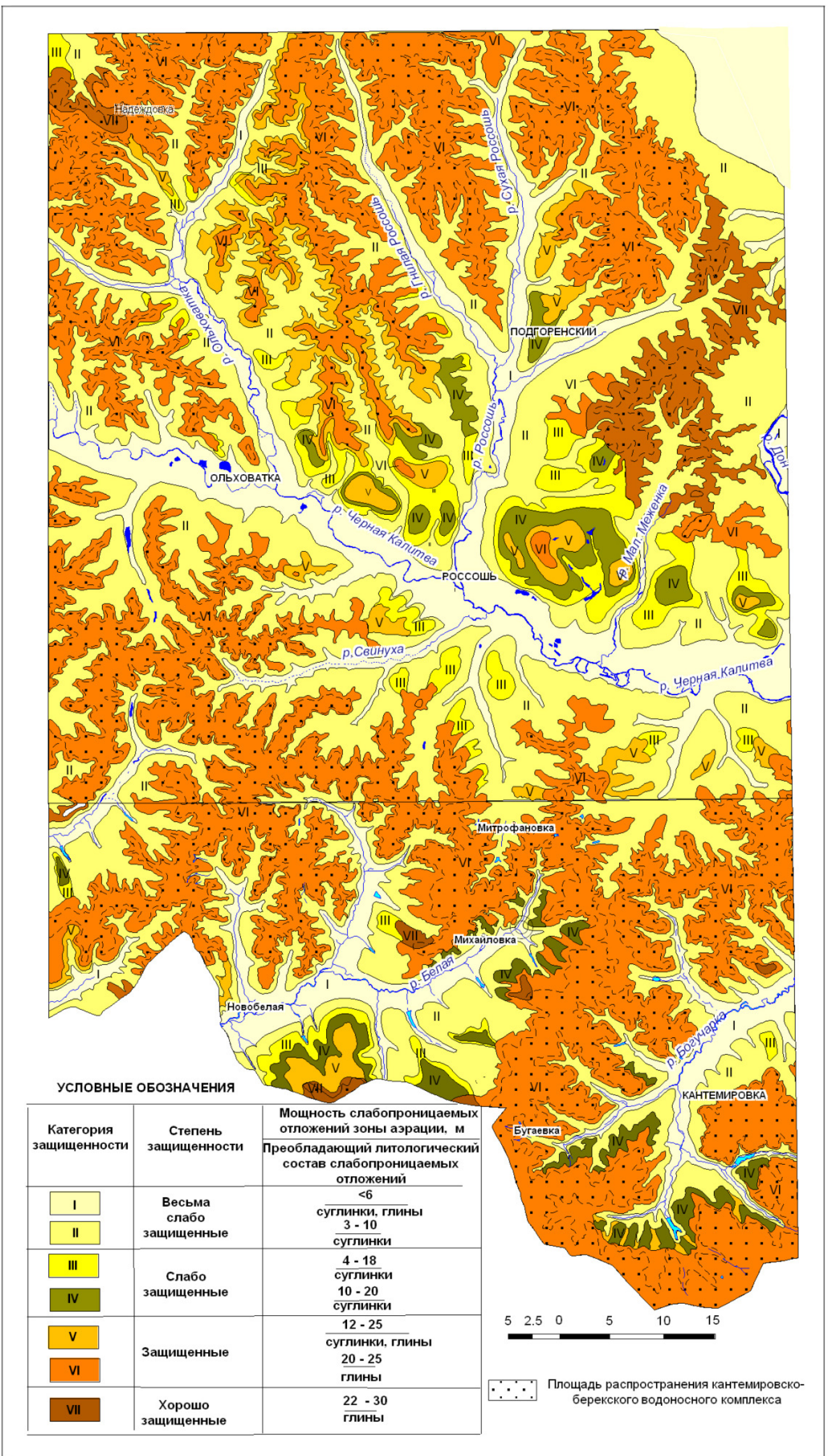

Puc.2. Схематическая карта защищенности от загрязнения верхнемелового водоносного комплекса (С. П. Пасмарнова, 2017 г.). 
Также участки защищенных от поверхностного загрязнения (V-VI категории) подземных вод рассматриваемого комплекса отмечены северо-восточнее и северо-западнее г. Россошь и южнее с. Новобелая, что обусловлено в первом случае наличием в разрезе зоны аэрации 15-20 метровой толщи аллювиальных глин неогенового возраста, во втором- повышенной мощностью (до 25 м) субаэральных суглинков.

Таким образом, защищенность от инфильтрации загрязненных стоков с поверхности земли кантемировско-берекского водоносного комплекса на большей части площади его распространения невысокая (I-III категории). Для подземных вод, приуроченных к верхнемеловым отложениям, в долинах рек всегда существует опасность загрязнения со стороны техногенных объектов. Хорошо защищен от поступления загрязняющих веществ верхнемеловой водоносный карбонатный комплекс на водораздельных пространствах и склонах водоразделов, где он перекрыт киевско-обуховским водоупорным горизонтом.

\section{ЛИТЕРАТУРА}

1. Пасмарнова, С. П. Геологическое строение зоны аэрации как фактор защищенности грунтовых вод от техногенного загрязнения / С. П. Пасмарнова, Ю. М. Зинюков // Научно-методические основы и практика регионального гидрогеологического изучения и картографирования: материалы второй Всероссийской научно-практической конференции. - М.: ВСЕГИНГЕО, 2001. - С. 68-70.

2. Пасмарнова, С. П. Новые принципы методики исследования геоэкологического состояния подземных вод/ С. П. Пасмарнова, А. Я. Смирнова, Е. Н. Кислякова //

ФГБОУ ВО «Воронежский государственный университет»

Пасмарнова Светлана Павловна, кандидат географических наук, дочент кафедры гидрогеологии, инженерной геологии и геоэкологии

E-mail: gidrogeol@mail.ru

Тел.: +7 (473)220 8980
Вестник Воронеж. гос. ун-та. Сер. Геология. - 2007 .- № 1. - C. $185-189$

3. Пасмарнова, С. П. Современный подход к оценке защищенности грунтовых вод / С.П. Пасмарнова, А. Я. Смирнова // Экологическая геология: научно-практические, медицинские и экономико-правовые аспекты : материалы междунар. науч.-практ. конф., 6-10 окт. 2009 г. - Воронеж, 2009. - C. 91-92

4. Гольдберг, В. М. Гидрогеологические основы охраны подземных вод от загрязнения / В. М. Гольдберг, С. Газда. М.: Недра, 1984. - 266 с.

5. Смирнова, А. Я. Грунтовые воды и их естественная защищенность от загрязнения на территории Воронежской области / А. Я. Смирнова, Л. В. Умнякова, В. М. Гольдберг - Воронеж: Изд-во ВГУ, 1986. - 108 с.

6. Холмовой, Г. В. Неогеновые и четвертичные отложения Среднерусской возвышенности / Г. В. Холмовой, Б. В. Глушков. - Труды научно-исследовательского института геологии Воронеж. гос. ун-та. - Вып. 1.- Воронеж: Изд-во Воронеж. гос. ун-та, 2001. - 220c.

7. Савко, А. Д. Объяснительная записка к атласу фациальных карт Воронежской антеклизы / А. Д. Савко [и др.]. Труды научно-исследовательского института геологии Воронеж. гос. ун-та. - Вып. 20.- Воронеж: Изд-во Воронеж. гос. ун-та, 2004. - 107 с.

8. Савко, А. Д. Литология и фации донеогеновых отложений Воронежской антеклизы / А. Д. Савко [и др.]. - Труды научно-исследовательского института геологии Воронеж. гос. ун-та. - Вып. 3.- Воронеж: Изд-во Воронеж. гос. ун-та, 2001. - 201c.

9. Савко, А. Д. Геология Воронежской антеклизы / А. Д. Савко. Труды научно-исследовательского института геологии Воронеж. гос. ун-та. - Вып. 12.- Воронеж: Изд-во Воронеж. гос. ун-та, 2002. - 165 c.

\section{Voronezh State University}

Pasmarnova S. P., Candidate of Geographical Sciences, Associate Professor of the Hydrogeology, Engeneering Geology and

Geoecology Department

E-mail: gidrogeol@mail.ru

Tel.: +7 (473)2208980 